\title{
EI Tesauro como experiencia patrimonial. Muebles e Inmuebles y sus
relaciones teminológicas
}

\section{Resumen}

El artículo -tras una reflexión previa sobre lo que supuso la elaboración del tesauro como puesta en práctica de un determinado entendimiento de lo patrimonial- esboza el proceso estructurante seguido con la terminología correspondiente a muebles e inmuebles del Patrimonio Histórico Andaluz, y apunta algunas de las relaciones básicas tenidas en cuenta en la elaboración de este lenguaje documental.

\section{Palabras clave:}

Tesauros / Patrimonio mueble / Patrimonio arquitectónico / Patrimonio urbano / Territorio / Andalucía / Integración disciplinar /Terminología

\section{Una experiencia patrimonial}

El recuerdo no es más que esa forma de pensamiento que siempre va acompañada del olvido. Pero hablar del Tesauro de Patrimonio me lleva, inevitablemente, a recordar esa experiencia donde se produjo el encuentro de un grupo de profesionales, interesados en aportar lo mejor de sus conocimientos al lenguaje patrimonial.

Es por ello que decir que el Tesauro es un proyecto de integración y normalización del lenguaje documental, que aspira a posibilitar las relaciones terminológicas del vasto y extenso mundo del Patrimonio, no es suficiente. $Y$ no lo es, porque su verdadera raíz no estuvo solamente en el planteamiento que de lo patrimonial se realizó en la investigación, sino en su puesta en práctica. El Tesauro fue un auténtico 'desafío de la globalidad' I desde la diversidad que lo patrimonial posee. Y surgió, precisamente, de la necesidad de poner en marcha -una vez más, ahora desde el lenguaje- la difícil labor de integrar mundos tan distintos.
Todos éramos conscientes de los caminos paralelos, e incluso divergentes, que las diversas disciplinas habían trazado en su acercamiento a lo patrimonial, por lo que -desde el primer momento- el Tesauro se convirtió en una puesta en escena de cada uno de los ámbitos de los que partíamos. Así, por encima de la Historia del Arte, de la Arqueología, la Antropología, la Geología, la Restauración, la Conservación y la Arquitectura - por nombrar las disciplinas que mayor presencia poseen en este tesauro- existía una disposición a incorporarse a una acción que no estaba exenta de riesgos. La pérdida de lo que uno era como oferta al 'Otro' se hacía generosa y recelosa al mismo tiempo. Perder lo que uno posee como más valioso a cambio de construir algo que fuese común estaba en el planteamiento.

Los largos y continuados debates fueron difíciles, no sólo porque suponían la renuncia a aquello que habíamos conseguido con nuestro esfuerzo -observando como se disolvía en aquel magma sin titularidad visible-; sino porque además entre nosotros se interponían las palabras -esos signos del lenguaje que, curiosamente, igual nos unen que nos separan.

Aunque unos más tarde que otros, todos, comenzamos a tener consciencia de que la ceremonia que allí nos había reunido era básicamente interpretativa. En el diálogo, las palabras se deslizaban y trasladaban de un sitio a otro destruyendo así ese estricto corsé al que habían estado sometidas durante tantos años. Veíamos entonces cómo las clasificaciones científicas saltaban por los aires y quedaban hechas trizas. Pero no se trataba de sustituir una jerarquía por otra -el tesauro es un lenguaje básicamente relacional, asociativo, y no jerárquico- sino de posibilitar lecturas múltiples ${ }^{2}$.

El reto había comenzado. Teníamos que encontrarnos con aquellos términos, jerarquías y conceptualizaciones que nos habían llegado al presente. El proceder no fue otro que el de nombrar con nuestra 
Es conveniente señalar que la división de este macrodescriptor en Objetos Inmuebles y Objetos Muebles no coincide con la división legal de los bienes patrimoniales, que siempre va a estar sujeta a los cambios administrativos que se produzcan, sino que responde al entendimiento mucho más primario de "lo fijo" y "lo móvil"

propia voz todo aquello que nos rodeaba. Esta labor fue también un acto de reconocimiento indescriptible porque, al prestarle nuestra voz, las palabras comenzaron a adquirir sentido y ahorificarse. Las disciplinas, disueltas en el medio patrimonial, adquirían otro rol: incorporándose constituían grupo; desdibujándose, conseguían alumbrar nuevos caminos; y separándose de lo que eran, posibilitaban relaciones insospechadas.

Todo ello se fundamentó en el método científico que, inspirado en la Teoría de Casos o Gramática de Casos, constituyó las reglas básicas del juego. Un marco científico que permitía la introducción de variables, convenciones del grupo, que surgían del dialogo y de la puesta en relación de los miembros con el lenguaje. Si el Tesauro, que se ha realizado, se considera un lenguaje abierto, dispuesto para que el usuario vaya estableciendo todas aquellas relaciones que considere oportunas; es precisamente porque así se fue construyendo. Porque, en su raíz, aquellos que lo estábamos elaborando, actuábamos ya como usuarios del mismo.

Sin duda, un entendimiento de lo patrimonial estaba detrás de ello, latente. No se trataba ya de una operación multidisciplinar como las que tan cacareadamente habíamos demandado durante varias décadas. Estábamos inmersos en una acción interdisciplinar donde las disciplinas, y aquellos que la portaban, se abrían a la comprensión del otro.

Debo reconocer que el gran logro del Tesauro fue conseguir que el deseo de alteridad se consumara en buena parte, y que -concluida esta fase de dos largos años de encuentro- cada profesional acabase siendo menos profesional en su materia: el historiador menos 'histórico', el arqueólogo menos 'arqueológico', el antropólogo menos 'antropológico', el geólogo menos 'geológico' y el restaurador y el arquitecto menos técnicos de cada una de sus materias. Una pérdida aparente que se había convertido, sin embargo, en amplitud; porque el construir algo que nos era común nos había hecho más globales y, por tanto, más patrimoniales.

\section{La terminología de muebles e inmuebles en el tesauro}

Es ahora, después de esta experiencia, cuando cada uno podemos comenzar a comprender mejor los datos particulares. Intentaré explicar de qué manera aparece recogida la terminología de muebles e inmuebles y cual ha sido el entendimiento de ella.

Diremos que como metodología recurrimos al macrodescriptor Objetos ${ }^{3}$, recogido en la gramática de Casos, denominación bajo la cual agrupamos tanto muebles como inmuebles. Es conveniente señalar que la división de este macrodescriptor en Objetos Inmuebles y Objetos Muebles no coincide con la división legal de los bienes patrimoniales, que siempre va a estar sujeta a los cambios administrativos que se produzcan, sino que responde al entendimiento mucho más primario de "lo fijo" y "lo móvil"; a pesar de que en el mundo en que vivimos estas categorías comienzan a ser también bastante relativas.

Así, hemos considerado Objetos inmuebles aquellos que normalmente no se mueven, permaneciendo ligados a un lugar. En ese sentido serán objetos inmuebles las denominaciones comunes de los espacios territoriales o urbanos (caminos, calles, ciudades), edificios, construcciones, etc. y todas aquellas cosas que permanecen unidas a los mismos, de manera que si son retiradas produciría una pérdida cualitativa del inmueble. Por ejemplo, es un objeto inmueble una casa palacio y, con ella, sus dependencias, sus columnas, sus arcos, sus puertas y ventanas.

En contraposición a este concepto se consideran Objetos muebles aquellos que se pueden trasladar de una parte a otra, porque su razón de ser no es la 
de pertenecer a ningún inmueble en concreto. Por ejemplo, una mesa, una silla o un cuadro.

A este respecto, la administración de patrimonio - consciente de la relación que determinados objetos muebles establecen con los inmuebles en los que se instalan- ha comenzado a proteger conjuntamente muebles e inmuebles con enorme acierto. Pero ello no es óbice para que nosotros en el Tesauro los diferenciemos.

Para terminar con los criterios que hemos tomado respecto a esta macroestructura de Objetos diremos que -tal y como se indica en la nota aclaratoria del mismo- quedan excluidos los materiales y los productos alimenticios; recogiéndose bajo el macro 'Materiales' y el listado asociado 'Alimentos'. Aunque ambos pueden llegar a gozar del carácter de objetos al ser "sustancias físicas naturales o transformadas por el ser humano", hemos establecido una diferencia que nos parece fundamental. Materiales y alimentos hacen referencia a materia prima o materia con un primer grado de transformación, pero para ser considerados objetos en el tesauro necesitan una puesta en relación con una actividad diferente de la de su propia producción. Por ejemplo, azulejo y ladillo serían materiales y zócalo y muro serían objetos inmuebles. Del mismo modo papel sería material y estampa sería objeto mueble, concretamente documento 4

Realizadas estas aclaraciones sobre el macrodescriptor Objetos, sería conveniente explicar como se han estructurado los Objetos Inmuebles y los Objetos Muebles que se incluyen en él. En primer lugar, y con objeto de facilitar la búsqueda al usuario, pensamos que era bastante operativo diferenciar dos grandes grupos de inmuebles: aquellos que pertenecen al ámbito territorial, incluido lo urbano como parte del territorio, y aquellos que pertenecen al ámbito edificatorio. Aún así, existían inmuebles que se resistían a formar parte exclusiva de uno de estos ámbitos -por su especifidad o por poder pertenecer indistintamente a ambos-y decidimos dejarlos fuera directamente relacionado con los Objetos Inmuebles. Este fue el caso de los megalitos, las sedes y los yacimientos arqueológicos.

En los inmuebles del ámbito territorial diferenciamos entre Asentamientos, Infraestructuras Territoriales, Espacios Libres, Zonas Verdes, Complejos de Perforación y Complejos Extractivos. Como se puede observar los descriptores no responden a ningún criterio clasificatorio sino a los niveles de coherencia que en cada momento el grupo iba introduciendo en la investigación. Los inmuebles están aquí recogidos bajo la lógica que cada una de sus notas de alcance indican y desde la confluencia del entendimiento de los diversos campos de conocimiento. Por tanto, el modo de aparecer no responde a la lógica de ninguna disciplina sino a la del encuentro de todas. Será más tarde cuando el usuario el que introduzca su propia estructura desde su utilización.
Del mismo modo los inmuebles del ámbito edificatorio recogen edificios, dependencias y partes de éstos, elementos constructivos e instalaciones. Tanto los edificios como sus dependencias aparecen con las denominaciones comunes referidas, generalmente, al uso de los mismos. $Y$ aunque somos conscientes de los problemas que conlleva la aceptación de la tipología funcional, al menos quedaba más clara que cualquier intento tipológico ${ }^{5}$ de otra índole.

Así como con los Objetos Inmuebles el nivel de coherencia de agruparlos por ámbitos era claro, en la medida en que ocupan un lugar y que normalmente no se trasladan; con los Objetos Muebles el criterio de agrupación tuvo que responder a una indización más plural, debido, sobre todo, a la diversidad de procedencias de los mismos. Existen pues 21 entradas o descriptores que abren la búsqueda de los términos de estos objetos. A pesar del elevado número, consecuencia del complejo mundo al que pertenecen, pensamos que son de fácil localización por el usuario.

Habrá que advertir que aquí conviven diversos modos de agrupación de estos términos cuyos criterios generales podrían resumirse en tres grandes grupos. El primer criterio ha sido destacar aquellos grupos de objetos que de alguna forma vienen siendo históricamente reconocidos en el ámbito patrimonial como objetos de estudio: Documentos, Esculturas, Dibujos, Pinturas y Fotografías. En segundo lugar existen otros grupos de objetos que responden a la consideración de la actividad con la que se relacionan o en la que son utilizados: Ajuares, Indumentaria. Objetos textiles. Prendas, Objetos de intercambio, Objetos deportivos. Objetos recreativos, Objetos mágico-religiosos, Objetos individuales y Vehículos de transporte. Y por último, recogemos varios grupos de objetos bastante consolidados bajo los descriptores Mobiliario, Instrumentos musicales, Instrumentos tecnocientíficos y Utensilios. De ellos Mobiliario y Utensilios, además de ser los más numerosos, contienen términos de las más variada procedencia; por lo que su agrupación ha sido bastante compleja. Los criterios han respondido casi siempre a su función primaria, de manera que su adscripción a algún grupo fuese mucho más genérica que específica.

Tras esta breve explicación sobre la estructuración de la terminología de muebles e inmuebles en el Tesauro de Patrimonio Andaluz, no debemos dejar de señalar que cualquier utilización de estos términos siempre puede servirse de los términos relacionales (TR) que en cada descriptor se indican, porque ellos constituyen el auténtico valor del tesauro. Los cruces terminológicos con acontecimientos, actividades, técnicas, agentes, etnias, estructuras, materiales, atributos, estilos, periodos, o con aspectos asociados y listados auxiliares; son los que pueden dibujar la verdadera dimensión del instrumento que ahora poseemos. 
Decir también que la terminología autorizada siempre ha respondido a aquellas palabras más propias al ámbito de nuestra comunidad autónoma, pero los sinónimos (UP) y sus relaciones convierten al tesauro en un instrumento global, con posibilidades de organizar, conocer y reconocer la problemática patrimonial de cualquier lugar de nuestro planeta. En ese sentido, el tesauro también ha dejado de oponer lo universal a lo concreto, superando esa antigua dialéctica entre lo global y lo local; y, sobre todo, su carácter de abierto lo dispone a las sucesivas transformaciones que se avecinen.
I. Expresión que da título a un artículo de Edgar Morin en él que nos habla de la necesidad de movilizar el todo desde una reforma del pensamiento que engendrará un pensamiento del contexto y de lo complejo. Un pensamiento donde "por aleatorio o difícil que sea el conocimiento de los problemas-clave del mundo debe intentarse so pena de imbecilidad cognitiva"; y donde "hacerse consciente es romper con la ilusión de creerse propietario de la racionalidad." (Revista Archipiélago, $\left.n^{\circ} 16\right)$

2. Esto no estuvo suficientemente claro y algunos miembros de la 'comunidad científica' desconfiaron de esta operación. No sabemos si porque la renuncia disciplinar que el tesauro conllevaba era demasiado dura para ellos, o porque entendieron que esta forma de abordar lo patrimonial era poco científica. Sin duda en la base de todo ello estaba presente una adscripción ciega a la epistemología lógico-normativa y una incomprensión de la epistemología genética.

3. La nota de alcance correspondiente a este macrodescriptor dice así: "entes materiales y tangibles no vivos, fijos (inmuebles) o móviles (muebles), productos finales de las transformaciones realizadas por el hombre, incluyendo los instrumentos y utensilios de origen natural o antrópico empleados en la transformación. Entre otros, edificios, espacios, imágenes, documentos, herramientas, restos, etc. Se excluyen los materiales, ubicados en macro aparte, y los productos alimenticios elaborados, en listado asociado.
4. De todas formas no debemos olvidar que el objetivo del tesauro no es clasificar sino indizar y normalizar el vocabulario, por lo que en caso de duda ante cualquiera de estos términos, podría incluirse en varios macros (caso de polijerarquía) o permanecer en aquel que consideremos más habitual, remitiéndose al menos usual mediante una llamada como término relacional.

5. En la medida que las investigaciones tipológicas no superaron nunca el nivel de series tipológicas, y dado el marco de investigación en el que se sitúa el tesauro, pensamos que lo más adecuado era tomar la opción indicada como umbral de búsqueda. Aunque los niveles de contradicción permanecen, podíamos señalar, como ejemplo, el criterio adoptado en la aplicación del tesauro a las Bases de Datos del SIPHA. En ellas, hemos decidido aceptar como tipología, la denominación común referida al uso para la que el edificio fue concebido, siempre y cuando los diferentes usos y transformaciones no hayan resultado esenciales en su configuración espacial. 